\title{
UTILITY OF INTRATHECAL FLUORESCEIN FOR LOCALIZATION OF TEMPORAL BONE CEREBROSPINAL FLUID LEAK.
}

\author{
Izquierdo.A, Martí. A, Sempere. M, Gil.F, De Andrés.J
}

Consorcio Hospital General Universitario de Valencia, Spain.

\section{BACKGROUND}

Intrathecal fluorescein is used for intraoperative localization of cerebrospinal fluid leak (CFL) mainly in endoscopic endonasal surgery. Low dosis of intrathecal fluorescein has been reported in the literature as a safe tecnhique. We describe its utility as an adjuvant for localization of CFL in the middle ear.
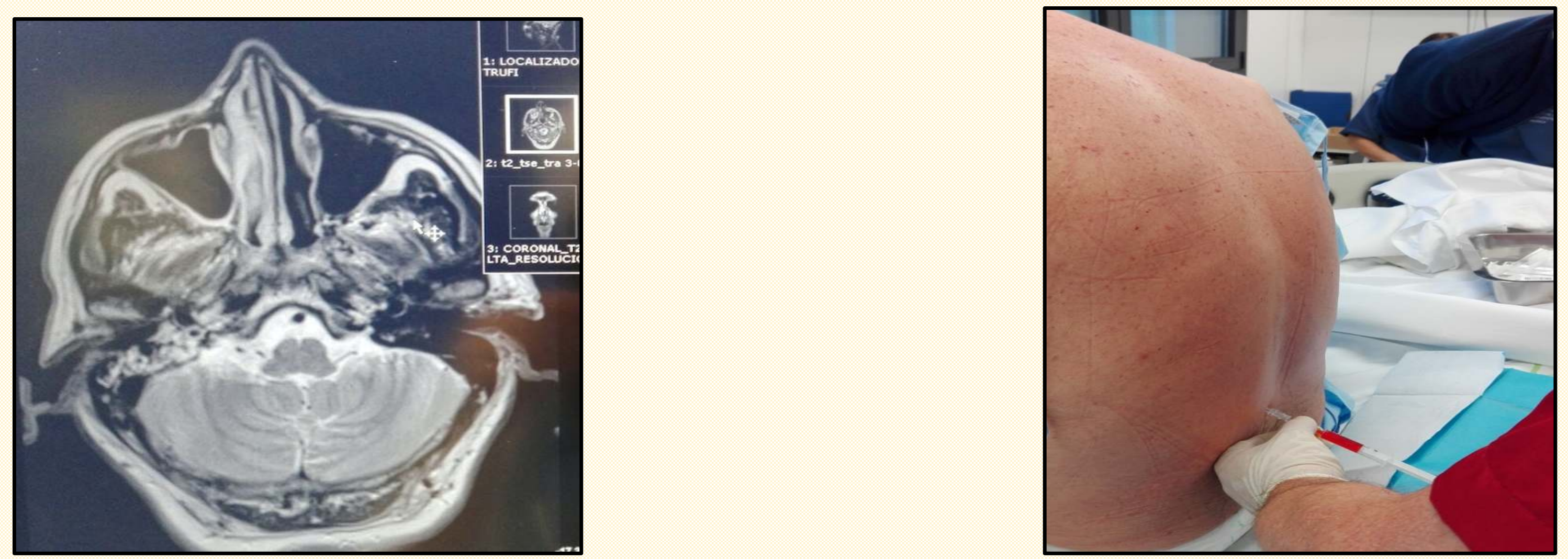

\section{METHODS}

A case of 68 years old man with spontaneous rhinorrhea and magnetic resonance imaging of pneumocephalus and right petrous bone defect is exposed. Suspecting CFL was scheduled for surgical repair. Previous surgery an intrathecal administration of $1 \mathrm{ml}$ of fluorescein $5 \%$ solution was administrated slowly for localize the exact site of the leak. Later general anaesthesia was performed.

\section{RESULTS}

After 35 minutes from intrathecal injection cerebrospinal fluid dyed with the fluorescein was observed by endonasal endoscopy. The exact origin of the leakage was detected from the posterior fossa through mastoid cells by transmastoid approach. Surgical closure of the leakage was performed with fascia and muscle succesfully. The patient recovered without neurological complications in the postoperative period.

\section{CONCLUSIONS}

Intrathecal fluorescein is a simple and safety technique useful for detection of CFL at different localizations, including the middle ear.

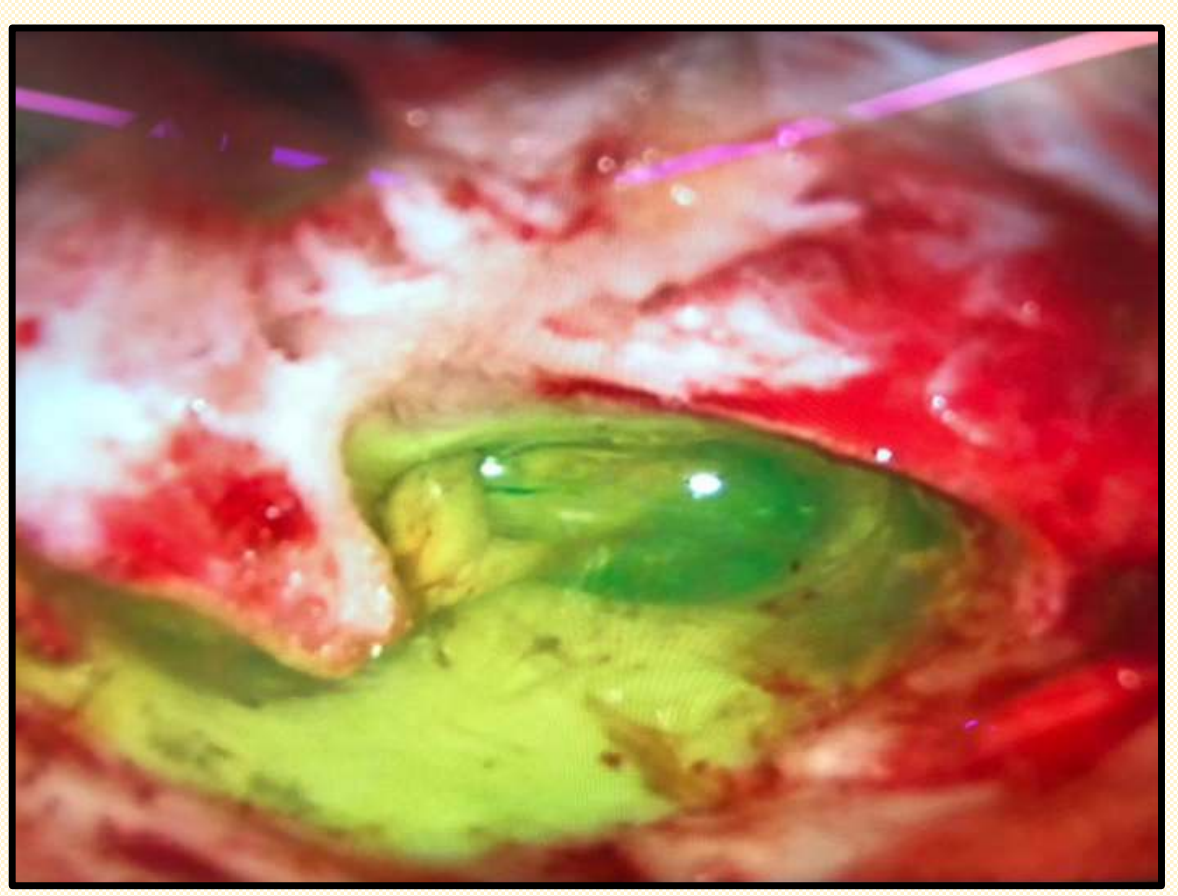

